\title{
Reconstruction of humins formation mechanism from decomposition products: A GC-MS study based on catalytic continuous flow depolymerizations
}

\author{
Layla Filiciotto $^{\mathrm{a}}$, Alina M. Balu ${ }^{\mathrm{a}}$, Antonio A. Romero ${ }^{\mathrm{a}}$, Carlo Angelici ${ }^{\mathrm{b}}$, Jan C. van der Waal ${ }^{\mathrm{b}, \mathrm{c}}$, \\ Rafael Luque $\mathrm{a}^{\mathrm{a}, \mathrm{d}, *}$ \\ a Departamento de Quimica Organica, Universidad de Cordoba, Campus de Rabanales, Edificio Marie Curie (C-3), Ctra Nnal IV-A, Km 396, Cordoba, Spain \\ b Avantium Chemicals, Zekeringstraat 29, 1014 BV, Amsterdam, the Netherlands \\ c TNO Netherlands Organization of Applied Scientific Research, Leeghwaterstraat 44, 2628 CA, Delft, the Netherlands \\ d Peoples Friendship University of Russia (RUDN University), 6 Miklukho Maklaya str., 117198, Moscow, Russia
}

\section{A R T I C L E I N F O}

\section{Keywords}

Humins

Biomass valorization

Hydrogenation

Continuous flow

Structural identification

\begin{abstract}
A B S T R A C T
Humins, a by-product of biomass chemical conversion technologies, still present controversies in their structural and mechanistic identification. Traditional studies of the structure and mechanism have focused so far on their syntheses from key molecules (sugars, HMF) and spectroscopic analyses of the as-synthesized oligomers/macromolecules. Herein, we propose structural and mechanism insights based on a novel down-up approach involving the decomposition of humins via catalytic reactions in continuous flow and interpretation of product molecules. The apparent co-existence of different mechanisms proposed in literature is observed upon product distribution analysis, and the key molecules taking part into humins formation are identified, including furanics, levulinates, sugar-derived molecules, and others. This work shows the complexity of humins formation, and their need of valorization.
\end{abstract}

\section{Introduction}

The continuous worldwide increase of population density (projected to 9.8 billion by 2050) [1], depletion of clean fossil-based resources (thus higher consumer price and more intensive purification technologies), and the importance of climate change mitigation by reducing green-house gases emissions $\left(<2^{\circ} \mathrm{C}\right.$ global temperature increase) [2], call for the development of renewable and benign technologies, for instance biomass conversion [3-8]. Depending on the conversion technology (microbial fermentation $v$ s. chemical transformation), the transformation of lignocellulosic biomass (a complex structure comprised of lignin, cellulose, and hemicelluloses which does not compete with food-required biomass) [9] can yield a variety of important platform chemicals (Scheme 1). In particular, hydrolysis in alcoholic media (e.g. methanol, $\mathrm{MeOH}$ ), yields to 5-methoxymethylfuran-2-carbaldehyde (MMF), the ether counterpart of important platform chemical, 5-hydroxymethylfurfural (HMF).

An example of the advantage of biomass-conversion strategies lies in the production of bio-based plastics. In fact, a recent Life Cycle Assessment (LCA) on traditional bioplastics (e.g. bio-polyethylene, -polyamides, -polylactic acid) shows an astonishing possible reduction of up to 316 million tons of $\mathrm{CO}_{2}$-eq. per year with the substitution of less than $66 \%$ of fossil-based plastics [10]. Parallel to traditional bio- plastics, the new platform chemicals that can be produced from biomass conversion (e.g. furanics as opposed to aromatics) can open new possibilities into the production of new bio-based plastics. For instance, polymerization of 2,5-furandicarboxylic acid (FDCA) and monoethylene glycol (MEG) yields PEF (polyethylene furanoate), a plastic with improved properties compared to PET (polyethylene terephthalate) $[11,12]$. The production of FDCA relies on the acid-catalyzed hydrolysis of (lignocellulosic) biomass and sugars (i.e. glucose, fructose) into HMF, and subsequent selective oxidation. However, the first conversion step into HMF favors the production of insoluble, black, oligomeric/macromolecular by-products denominated as humins with yields up to $30-40 \mathrm{wt} \%$ [13-15]. Minimization of humins can be achieved by utilizing biphasic solvent systems [16-18], or by employing ionic liquids [19], but their formation is unavoidable and is influenced by process conditions, including temperature, $\mathrm{pH}$, residence time, substrate nature and concentrations, solvent systems, and catalysts. For this reason, humin by-products may not have a univocal structure and/or mechanism of formation. However, understanding the classes of products involved in their formation can aid their minimization by benign and economic strategies, and/ or valorization to high-added value products.

So far, structural identification has been carried out with a variety of techniques comprising FT/ATR-IR; $1 \mathrm{H},{ }^{13} \mathrm{C}$ and 2D NMR; elemental analysis; pyrolysis GC-MS; and Raman spectroscopy by synthesis of humins with either fructose, glucose, cellobiose, and/or HMF [20-25].

\footnotetext{
* Corresponding author at: Departamento de Quimica Organica, Universidad de Cordoba, Campus de Rabanales, Edificio Marie Curie (C-3), Ctra Nnal IV-A, Km 396, Cordoba, Spain.

E-mail address: q62alsor@uco.es (R. Luque)
} 


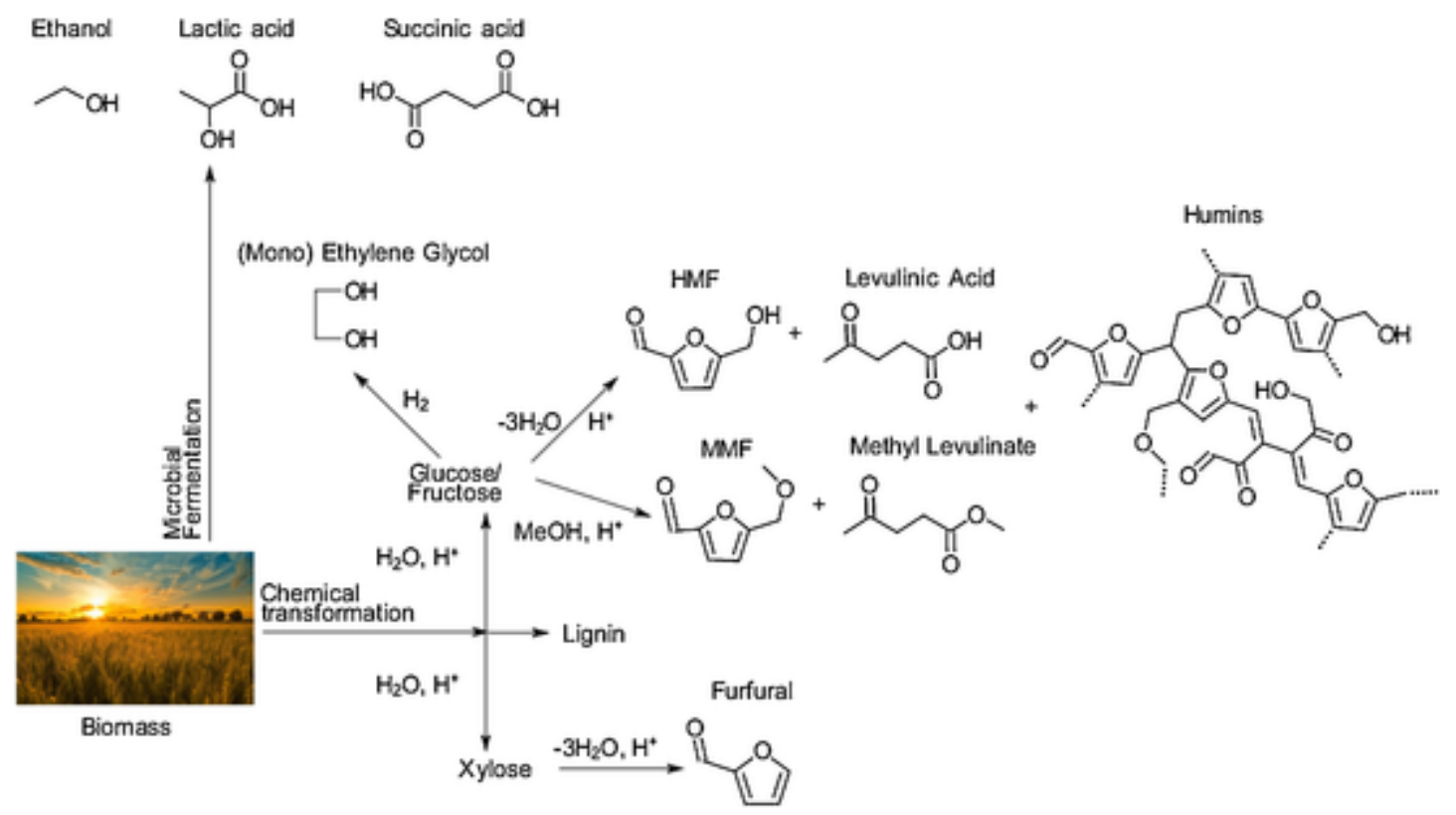

Scheme 1. Products and by-products of the biomass conversion technologies via microbial fermentation or chemical transformation, focused on acid-catalyzed hydrolysis.

Higher incorporation of HMF was observed in the fructose-derived humins due to kinetics of formation [26]. Generally, humins are believed to display an oligo/macromeric furanic backbone with short aliphatic chains and ether bonds, given by a random polycondensation of the molecules involved in the carbohydrates acid hydrolysis (e.g. HMF) [[24-28]]. In particular, 2D-NMR showed the presence of $\mathrm{C} \alpha$ and to a smaller extent $\mathrm{C} \beta$ self- and aliphatic linkages [28], also seen from IR analyses [29]. The $\alpha$ and $\beta$ were in fact crucial nucleophilic centres in the formation of humins from HMF [30]. Ketone, hydroxyl, carboxylic, and/or aldehyde groups have been evidenced as functionalities in bulk structural analysis [31]. The overall elemental composition of humins is of the order of ca. $65 \mathrm{wt} \% \mathrm{C}, 30 \mathrm{wt} \% \mathrm{O}$, and $5 \mathrm{wt} \%$ $\mathrm{H}$ [32]. Recently, Constant et al. quantified the carbonyl concentration of industrial humins, setting it at $6.6 \mathrm{wt} \%$ [33]. Traditional humins possess high and low molecular weight fractions, whose property is attributed to the length and complexity of the oligo/macromeric chains [34]. In fact, emission and excitation UV-vis spectra of aqueous and organic fractions of humins show the presence of three fluorescent species, given by different conjugated chain lengths and complexity [35]. In general, we can consider humins as a complex matrix of different polymeric chains comprised of conjugated furanic rings and oxygenated and aliphatic linkages, which resemble the structure of early hydrothermal carbons (HTC) from carbohydrates (Scheme 2) [36].

The mechanism of humins formation is still a matter of debate and controversy in the scientific community. In fact, due to the apparently random nature of the polycondensation network of reactions, different mechanisms have been proposed in literature mainly considering HMF as key trigger for humins formation. In fact, the presence of aromatic furanic bonds was detected in all fructose, glucose, and HMF-derived humins, suggesting the importance of the latter molecule [30]. Based on Gibbs free energy values for various HMF conversions, the formation of condensation products (HMF/HMF, HMF/fructose) is favored $\left(5-10 \mathrm{~kJ} \mathrm{~mol}^{-1}\right)$ as opposed to levulinic acid formation $\left(63 \mathrm{~kJ} \mathrm{~mol}^{-1}\right)$ [20]. Sumerskii et al. proposed a series of parallel mechanisms involved in the formation of humins by-products, including aldol addition, incorporation of levulinic acid, and acetylization of furanic moieties [34]. In particular, it was proposed that carbonyl-containing intermediates would lead to a branched humins structure containing acetal bonds (Scheme 3). In contrast, acetal type of bonds were not incorporated in the model structure for humins proposed by van Zandvoort et al., but not excluded fully as a possibility due to the signal's attribution to either ether or acetal bonds [32].

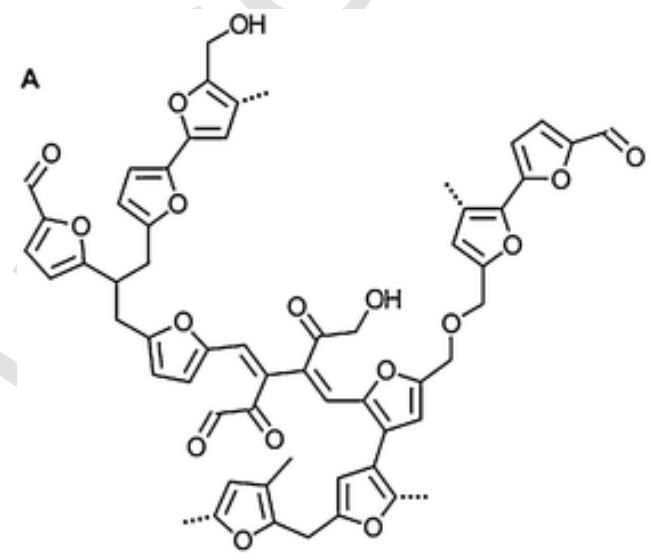

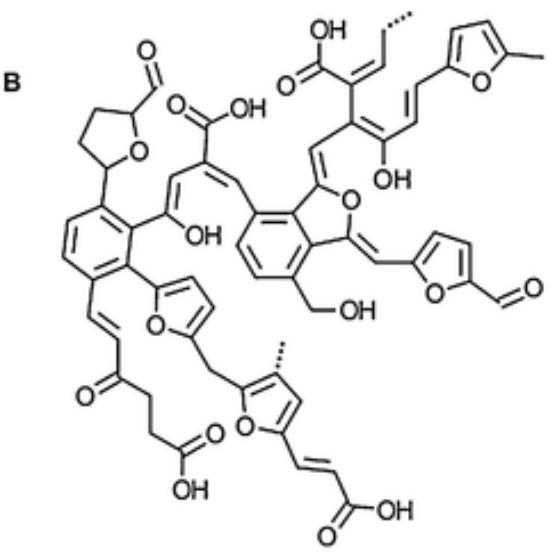

Scheme 2. Structures of humins (A, left) [25] and sugar-derived HTC (B, right) [36]. 


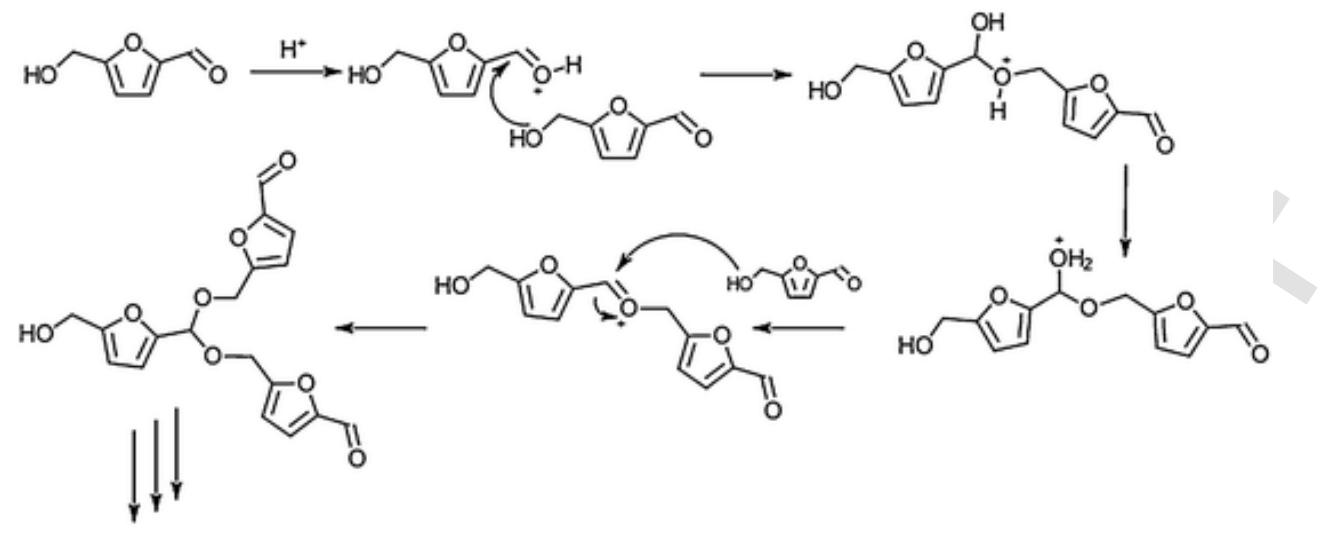

Humins

Scheme 3. Mechanism of humins formation proposed by Sumerskii et al. yielding branched HMF moieties with acetal bond [34].

First proposed by Hovart in a ${ }^{13} \mathrm{C}$ NMR study of the levulinic acid formation mechanism, the 2,3-addition of water on HMF is believed to yield to a highly reactive intermediate, 2,5-dioxo-6-hydroxyhexanal (DHH), which leads to polymerization products [37]. This theory was further developed by the work of Patil et al. where, although not detected spectroscopically, the humins formation proceeds via aldol condensation of DHH and HMF (Scheme 4), in competition with levulinic acid $[26,38]$. Another proposed intermediate involved in humins formation at a smaller extent has been identified as the 1,2,4-benzenetriol given by ring-opening of HMF by water addition, which polymerizes with other sugar-derived intermediates (Scheme 5) [39-41].

The further decomposition product of acid-catalyzed hydrolysis, levulinic acid, is usually believed to be stable and not reactive with regards the formation of humin by-products. However, it was found that the addition of levulinic acid (desired product) to the reaction mixture results in higher condensation, suggesting that levulinic acid is incorporated in the humins structure via carbocation formation [42].
It should be noted that the presence of both protons and water seems crucial in the formation of humins. Nonetheless, the presence of both is almost unavoidable in order to develop economically-feasible processes for biomass conversion which mainly employ mineral acids. For instance, the Biofine process dedicated to the production of furfural and levulinic acid relies on the use of dilute sulfuric acid, and the humins formation limits the overall process yields [43]. For this reason, further understanding of the governing mechanisms in humins formation may aid the development of cost-effective strategies for lignocellulosic biomass conversion. Also, structural characterization can give powerful insights into possible valorization opportunities for these by-products. However at present only limited studies have been conducted for [15,44-49].

Herein we propose structural and mechanistic identification of humin by-product formation by an approach different from the earlier proposed ones. Continuous flow hydrogenation and transfer hydrogenation (catalytic) decompositions in neutral conditions were employed in this study. The products were then qualitatively identified by GC-MS

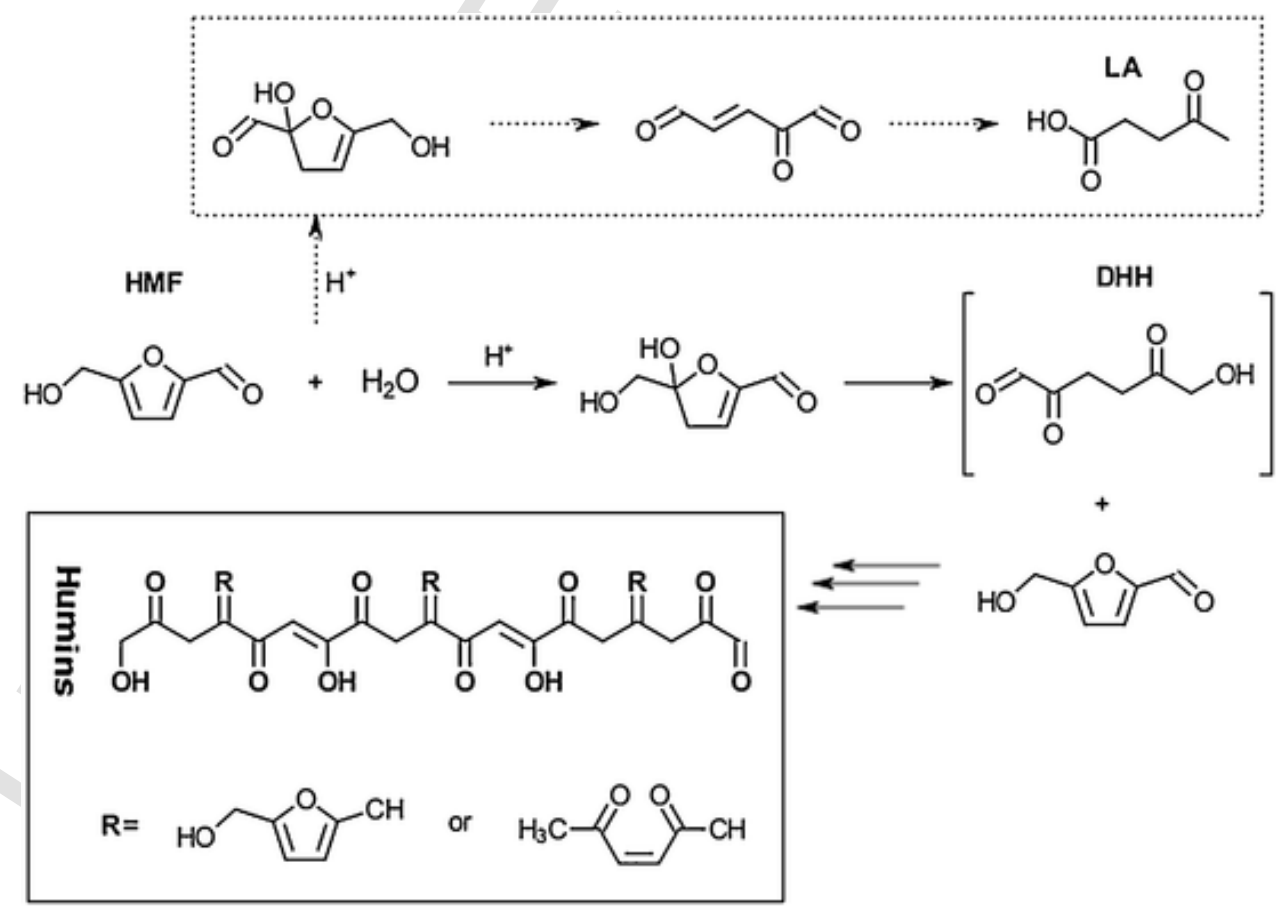

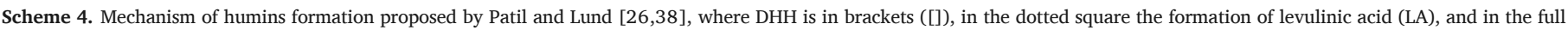
square the proposed humins structure. 


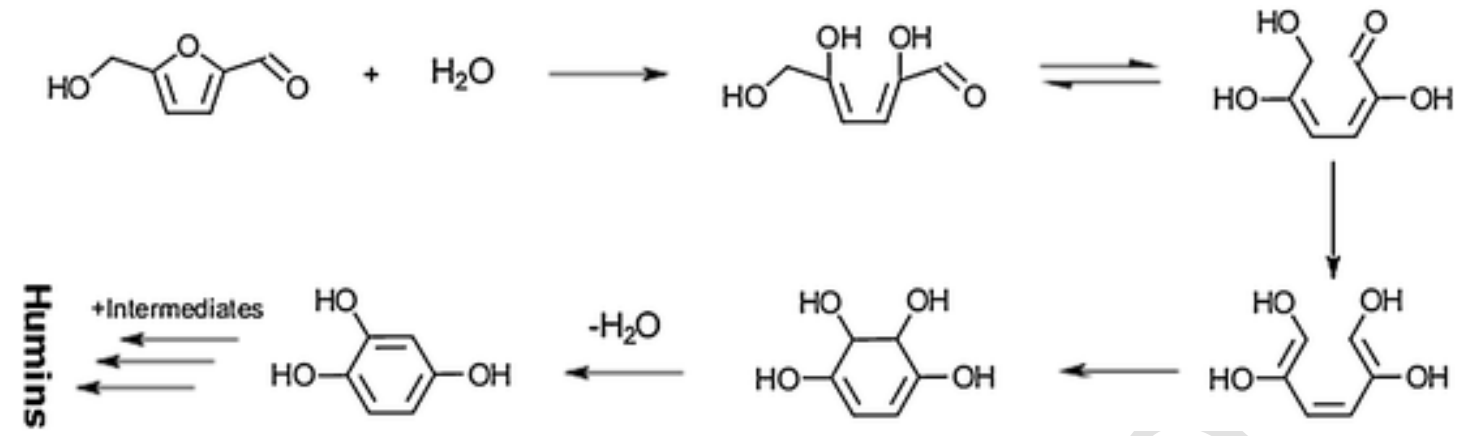

Scheme 5. Ring-opening hydrolysis of HMF towards highly-reactive intermediate 1,2,4-benzenetriol [39-41].

analysis and confirmed by UPLC which can give a better idea of the heterogeneous nature of these by-products, which include both starting materials and various (by-)products of the acid-catalyzed conversion of biomass. These findings will further stress the necessity of humins valorization for the economic feasibility of chemical biorefineries.

\section{Results and discussion}

Relative combined severity of humins

A combined severity evaluation of production processes indicates the harshness of process operating conditions, by incorporating values of temperature, time, and $\mathrm{pH}$ in two formulas [50]:

Table 1

Conditions and relative CSF (Combined Severity Factor) of the humins employed in this study, the humins synthesized in literature, and hydrothermal carbon.

\begin{tabular}{llll}
\hline & $\begin{array}{l}\text { Humins (this } \\
\text { study) }\end{array}$ & $\begin{array}{l}\text { Humins } \\
\text { (literature) }\end{array}$ & $\begin{array}{l}\text { Hydrothermal } \\
\text { Carbon }\end{array}$ \\
\hline $\begin{array}{l}\text { Feedstock } \\
\text { Temperature } \\
\left({ }^{\circ} \mathbf{C}\right)\end{array}$ & $\begin{array}{l}\text { Biomass/sugars } \\
180-200\end{array}$ & $\begin{array}{l}\text { Biomass/sugars } \\
180-210\end{array}$ & $\begin{array}{l}\text { Biomass/sugars } \\
180-250\end{array}$ \\
Environment & $\begin{array}{l}\text { Acidic water/ } \\
\text { alcohol }\end{array}$ & $\begin{array}{l}\text { Acidic water/ } \\
\text { alcohol }\end{array}$ & Water \\
Relative CSF & 1 & $25-50$ & $100-500$ \\
\hline
\end{tabular}

Severity Factor $(S F)=\log \left[t \times \exp \left(\frac{T-100}{14.75}\right)\right]$

Combined Severity Factor $(C S F)=S F-p H$

Upon calculation of the CSFs of the industrial process, the values from literature humins and hydrothermal carbon were normalized giving an arbitral number of 1 to the humins employed in this study. In comparison, the process for these industrial humins is at a lower process severity of 1-2 orders compared to the literature processes (Table 1). This particular result signals that lower extents of carbonization may have occurred to the humins, thus easier solubilization of said products and further decomposition into small organic molecules is easier. In fact, the humins employed in this study are viscous rather than solid (as traditional humins usually are), suggesting easier decomposition of the industrial humins into the comprising molecules.

\section{Transfer hydrogenolysis of humin by-products}

In the transfer hydrogenolysis of humins in isopropanol ( $1 \mathrm{wt} \%)$, a difference in catalytic effect between commercial 5\% Pd/C and Raney Nickel (rNi) catalyst was observed. At room temperature the relative HMF and MMF concentrations were similar for both catalysts, whereas at higher temperatures $\left(180^{\circ} \mathrm{C}\right)$ the Pd catalyst yields higher concentrations of the two molecules (Fig. 1). In fact, higher amounts of linear decomposition products were observed (e.g. 1,5-pentanediol) for the $\mathrm{rNi}$ catalytic system, which may signal the onset of hydrogenation or

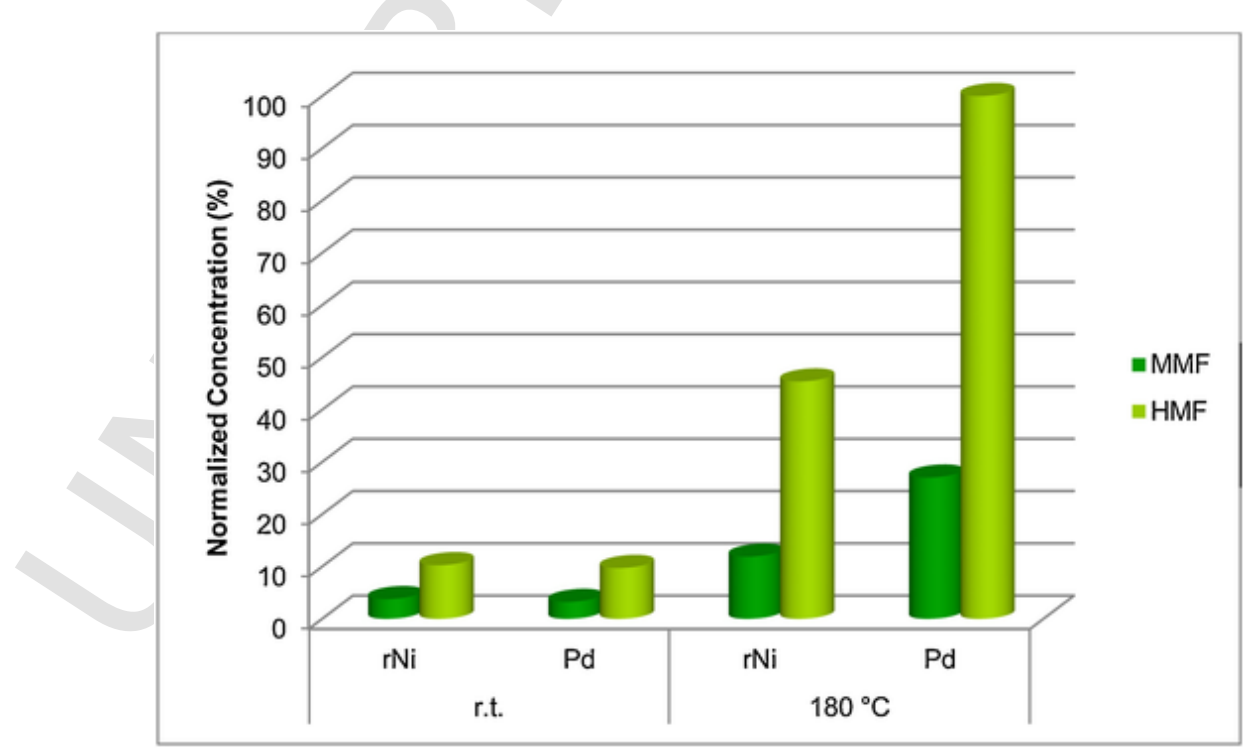

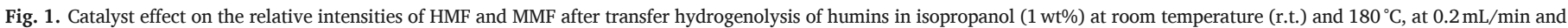
$15 \mathrm{bar}$, after $20 \mathrm{~min}$ of reaction time. 
decomposition of the major products, HMF and MMF, yielding wider product distribution. This could be expected thanks to the higher catalytic transfer hydrogenation activity of $\mathrm{rNi}$, as opposed to Pd catalysts [51], where the latter favors the conservation of the molecular structures obtained from humins. Obtaining HMF and MMF from decomposition reactions would be preferred for the overall economics of a PEF process, thus the $5 \% \mathrm{Pd} / \mathrm{C}$ was chosen for the following catalytic studies.

In our reaction conditions, HMF and MMF represent $>75 \%$ of the total mass balance in the decomposition products distribution. This is a first indication that indeed HMF, and its ether (MMF), are crucial in the formation of humins, being the main structural components, as already reported in literature [25-30,34,38-41]. MMF is generally not included in the common compound libraries, thus GC-MS fragmentation pattern, ATR-IR and NMR spectra of MMF are given in Fig. S1-3 of the Supplementary Data (SD).
The presence of HMF and MMF, however, could be also given by physisorption of these molecules on the humins surface, as seen elsewhere in literature [52]. In particular, research work on the same humins batches show the presence of up to $16 \mathrm{wt} \%$ of combined HMF and MMF (alkoxymethyl furaldehydes, RMF) for concentrated solutions [44]. GC-MS analyses of raw humins solutions used in this work (1 wt\%) do indeed show residual HMF and MMF but with integrated areas of at least 3 orders of magnitude lower than the areas of the product mixtures obtained after thermal or hydrogen-assisted reactions. In fact, at room temperature reactions (Fig. 1), 0.5\% residual HMF is observed for the blank reaction, and $c a .33 \%$ if in the presence of an hydrogenation catalyst $(5 \% \mathrm{Pd} / \mathrm{C})$. This phenomenon is not only a symptom of residual furanic monomers in the employed humins, but may also be a surprising catalytic activity at such low temperature. Furthermore, the relative HMF and MMF concentrations would increase thanks to heat treatment and presence of a catalytic system, as seen in Fig. 2.
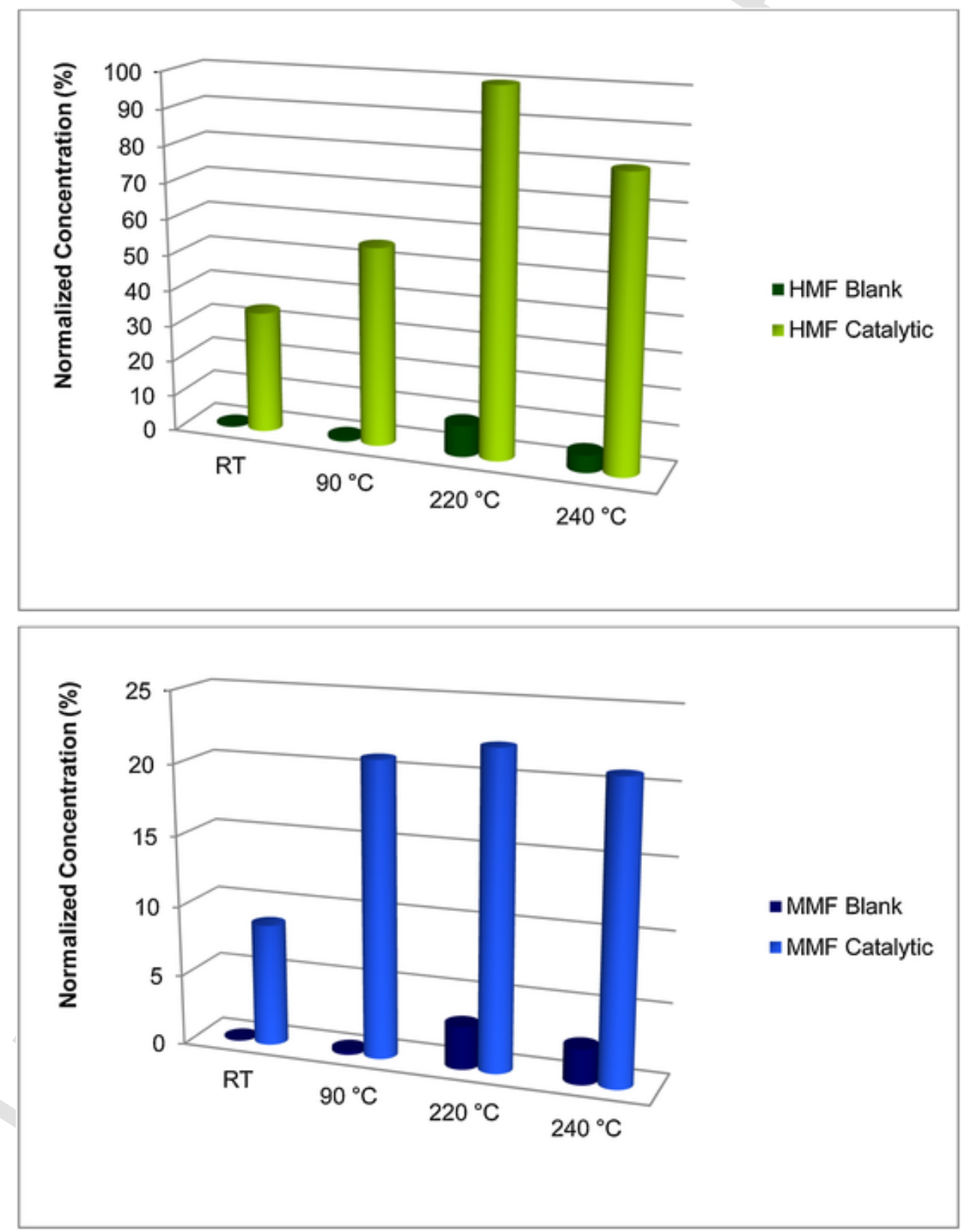

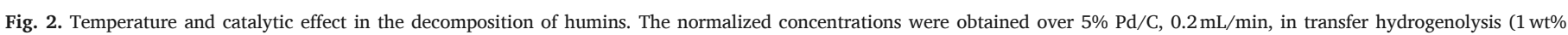
humins in isopropanol) after $20 \mathrm{~min}$ of time-on-stream. 
In particular, by considering the sum of the HMF and MMF GCMS peak areas of the TIC chromatogram of the i) non-catalytic blank, ii) room temperature catalytic reaction, and iii) catalytic hydrogenolysis at $90^{\circ} \mathrm{C}$, a $+765 \%$ increase of the peak areas sum is observed between $i$ ) and ii), and a $+460 \%$ increase between ii) and iii), signaling that the monomers observed in the reaction mixtures are products of the humins decompositions. Nonetheless, the presence of physically embedded HMF is indeed observed as it elutes in the blank reaction (non-catalytic) and at lower temperature conditions. On the other hand, the increase of the HMF concentration under transfer hydrogenolysis conditions suggests the presence of easily cleaved monomers, thus presenting weak oxygenated bonds, such as esters. The systematic co-presence of MMF signifies the incorporation of said molecule, possibly through its aldehyde functionality via aldol condensations/additions [30]. The lower incorporation of MMF is due to the protection of the hydroxyl group by etherification with methanol, making it more stable towards the humins formation, thus less reactive towards condensation reactions.

A higher HMF and MMF concentration at $220^{\circ} \mathrm{C}$ was expected as evidenced by TGA analysis [44]. In fact, a peak of decomposition at $210-220^{\circ} \mathrm{C}$ was observed with a mass loss of $c a .40 \%$, explaining the release of furanic molecules in oligomeric fractions. A slight decrease in relative intensity of the molecules at higher temperatures could be attributed to onset decomposition of the actual products at higher temperatures [53]. On the other hand, re-polymerization of the RMF monomers to humins in the same kinetic study is considered a parallel and co-existent mechanism. This phenomenon could explain why catalytic reactions in continuous flow would have extremely low catalyst lifetime ( $<60 \mathrm{~min}$ ), causing fouling and blockage of the continuous flow system, particularly at higher temperatures. Hence, an increase of the reactor pressure and consequent full blockage after $<40 \mathrm{~min}$ of time-on-stream was observed in most transfer hydrogenolysis reactions, signaling strong reactor fouling. In general, the main challenge of humins processing is the presence of heterogeneous molecules in solution, and thus coke formation. Although extreme dilutions of the feed may help reduce catalyst fouling (this work, $1 \mathrm{wt} \%$ solutions), fixed bed continuous flow reactors may not be feasible in their current form, requiring new engineering solutions for carbonaceous deposit removal.

\section{Catalyst deactivation and solvent effect}

To further assess the catalyst deactivation and solvent effect, the chosen catalytic system ( $5 \% \mathrm{Pd} / \mathrm{C})$ was investigated under hydrogenation conditions at mild reaction conditions $\left(90^{\circ} \mathrm{C}\right)$. By analyzing the relative HMF and MMF concentration over $60 \mathrm{~min}$ of reaction time (Fig. 3), an increase of the concentration is observed after $20 \mathrm{~min}$ of time on-stream, which is then drastically reduced after $60 \mathrm{~min}$. Although a wider product distribution is also obtained after $60 \mathrm{~min}$, by considering the sum of the areas of the TIC as opposed to $20 \mathrm{~min}$, a reduction of the total relative concentration is observed. Furthermore, the full blockage of the system's flow was a clear sign of reactor fouling.

In the mild temperature hydrogenation reactions $\left(90^{\circ} \mathrm{C}, 50 \mathrm{bar}\right.$, $0.3 \mathrm{~mL} / \mathrm{min}$ ), a solvent effect was also observed for the decomposition of humins in ethyl acetate solutions. Addition of $10 \mathrm{vol} \%$ of acetic acid increased the relative HMF and MMF concentrations (Fig. 4).

Acetic acid may act as an acid-catalyst in the hydrolysis of humins, but also as a promoter for the carbonyl group hydrogenation by partial protonation of the oxygenated function, as seen in literature for other hydrogenation reactions $[54,55]$. In fact, apart from higher concentrations of HMF and MMF, wider product distribution was observed when acetic acid was added. In particular, a third intense peak was observed after $60 \mathrm{~min}$ of reaction time and was identified as 5-acetoxymethyl-2-furaldehyde, the acetylated product of HMF, signaling the influence of acetic acid on the product mixture and solvolysis. The existence of this side-reaction decreases the selectivity of the conversion to a sole product, but may stabilize HMF against further decomposition reactions. On the other hand, it could be expected that the presence of acetic acid also catalyzes further condensation reactions to form humins and/or coke, leading to faster catalyst deactivation. In fact, a reaction of humins in glacial acetic acid (not analyzed) caused system fouling within $10 \mathrm{~min}$ of time-on-stream, which could be attributed to acid-catalyzed cross-linking.

Methanol and acetonitrile solutions caused rapid catalyst fouling, resulting in reactor plugging, and consecutive build-up and loss of sys-

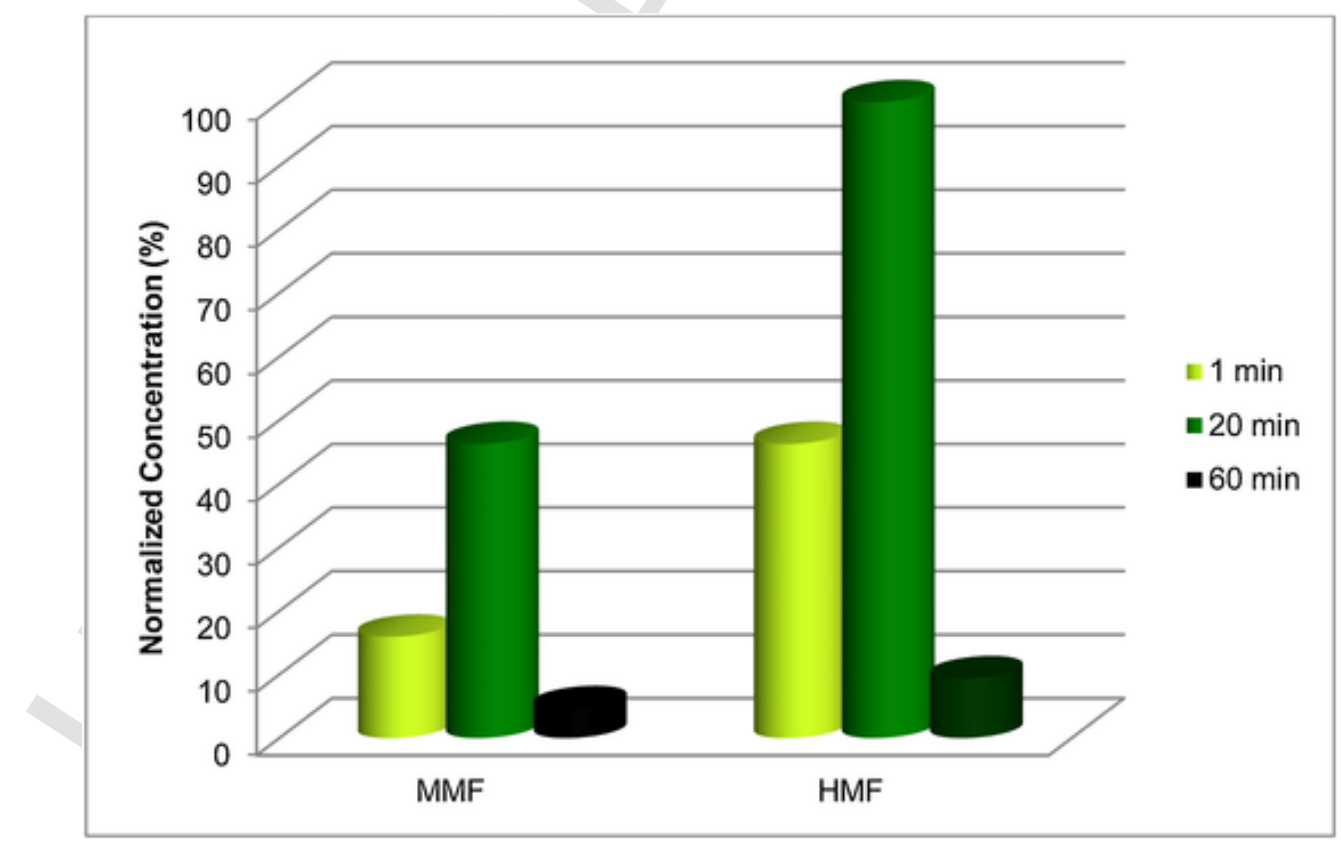

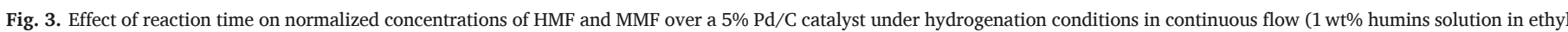
acetate, $\left.90^{\circ} \mathrm{C}, 50 \mathrm{bar}, 0.3 \mathrm{~mL} / \mathrm{min}\right)$. 


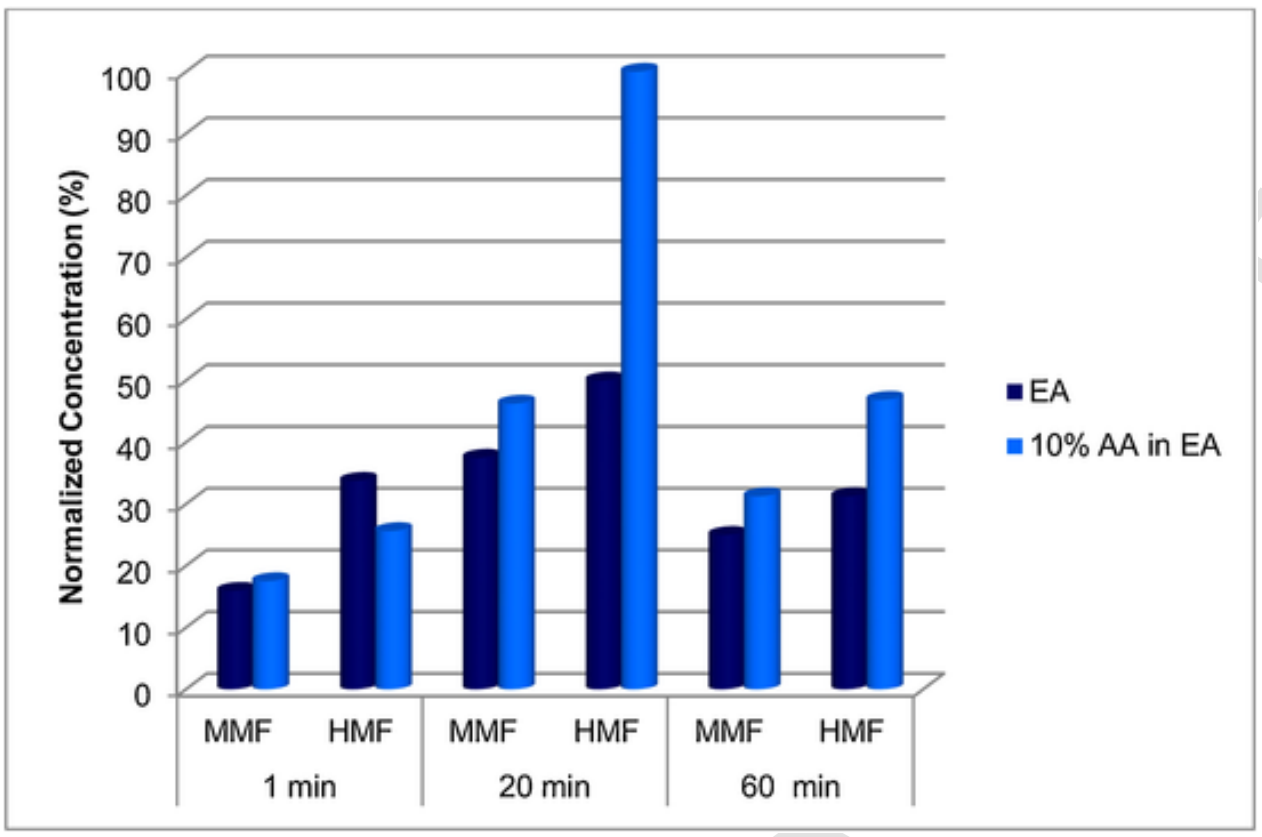

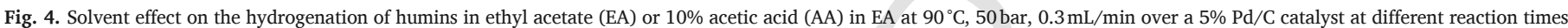
(1-60 min).

tem pressure. In fact, in these solvent systems reactions were possible for only $<20 \mathrm{~min}$. The solubility of humins had been addressed in several solvents [31], and reported as water $<$ acetonitrile $<$ methanol/diethyl ether/methyl levulinate, among others. In our solvent conditions ( $1 \mathrm{wt} \%$ humins solutions) we are probably dealing with a dispersion (even upon sonication and filtration), which further causes blockages in the plug flow reactors.

\section{Qualitative analysis of overall decomposition products}

Overall, the GC-MS analyses may give a small degree of uncertainty of the actual molecules observed. For this reason, in this study only molecules with a reversed match factor $>700$ are considered, and rather than looking at the molecules as such, an analysis of the functional groups and plausible reactivity with other known moieties were taken into consideration. The presence of furanics, isosorbide, levulinates, monosubstituted aromatics, and small organic acids were confirmed by UPLC analysis. Aside from small differences, such as the 5-acetoxymethyl-2-furaldehyde only appearing upon addition of acetic acid, or 5-methoxypentanol and similar open-ring compounds appearing at high hydrogenation conditions $\left(>180^{\circ} \mathrm{C}\right)$, consistent and coherent molecules were identified from the humins decompositions in both blank, transfer hydrogenolysis, and hydrogenation conditions with different concentrations (Table 2).

A total of five classes of compounds were identified from the (hydrogen-assisted) decomposition reactions, namely: $i$ ) furanics, ii) sugar-derived molecules, iii) levulinates, $i v$ ) aromatics, and $v$ ) small organic acids and other oxygenated molecules, including organic acids, alcohols, esters, aldehydes/ketones, and acetals. Furthermore, the formation of a number of compounds is expected but these could not be collected due to their volatility. For instance, molecules such as $\mathrm{CO}, \mathrm{CO}_{2}$, furan, formaldehyde, methanol, are expected. The latter in particular may explain the presence of methyl esters in the decomposition mixtures.

\section{Furanics}

The presence of HMF as the highest peak in our reaction mixtures confirms the crucial role of said molecule in the formation of humins, as already stated in literature $[24,25,27,28]$, present as loose and/or loosely bound. The ether counterpart, MMF, was also ubiquitously present in all decomposition samples. This suggests that although more stable towards humins formation thanks to the hydroxyl protection by etherification [39], the aldehyde functionality of MMF is prone towards aldol additions/condensation reactions, thus leading to humins. Also, humins release water upon pyrolysis (ca. $20 \mathrm{wt} \%$ ) as observed by Argawal et al. [56], thus partial hydrogenolysis of the ether MMF to HMF can be expected. All the remaining furanics $(<15 \%$ of product distribution) identified exhibit at least one oxygen functionality with only C1-C2 side linkages. This appearance stresses further the incorporation of furanics in the structure which would present only short bridging groups between furan groups. Ester, aldehyde, and hydroxyl side groups are predominant. The observation of cirsiumaldehyde, a dimer of HMF via an ether bridging bond, may support the mechanism proposed by Sumerskii et al. involving the formation of hemiacetal/acetal of HMF and may be produced by hydrogenolysis of the acetal functionality [34]. The aldehyde side-groups may undergo further condensation reactions, leading to the oligomeric molecules. Also the presence of a diol functional group in 1-(2-furyl)-1,2-ethanediol sustains the mechanism aforementioned by signaling the presence of an acetal bond [34]. Pd is known to cleave an acetal-carbonyl bond in favor of a diol under hydrogenation conditions [57]. However, the 1,2 positioning of the diol (instead of 1,1 ) would rather hint towards the formation of a cyclic acetal, following its reaction with a carbonyl functionality, which could explain the dismissal of the acetal presence, although observed, in NMR analysis [25]. Considering the (acidic) environment of humins formation and the nature of the involved molecules (i.e. sugar chemistry), the formation of cyclic acetal can be expected (also seen elsewhere) [58], and incorporated to a very small extent. The other furanic molecules instead simply imply the multifaceted nature of humin by-products, involving different oxygen functionalities of the furanic molecules, with a facile incorporation in the structure via short linkages.

\section{Sugar-derived molecules}

Sugars and sugar-derived molecules were expected based on the literature data $[26,39]$. These molecules have been detected already from decomposition/hydrogenation at room temperature, suggesting that it 
Table 2

Identified molecules in the (catalytic) decompositions.

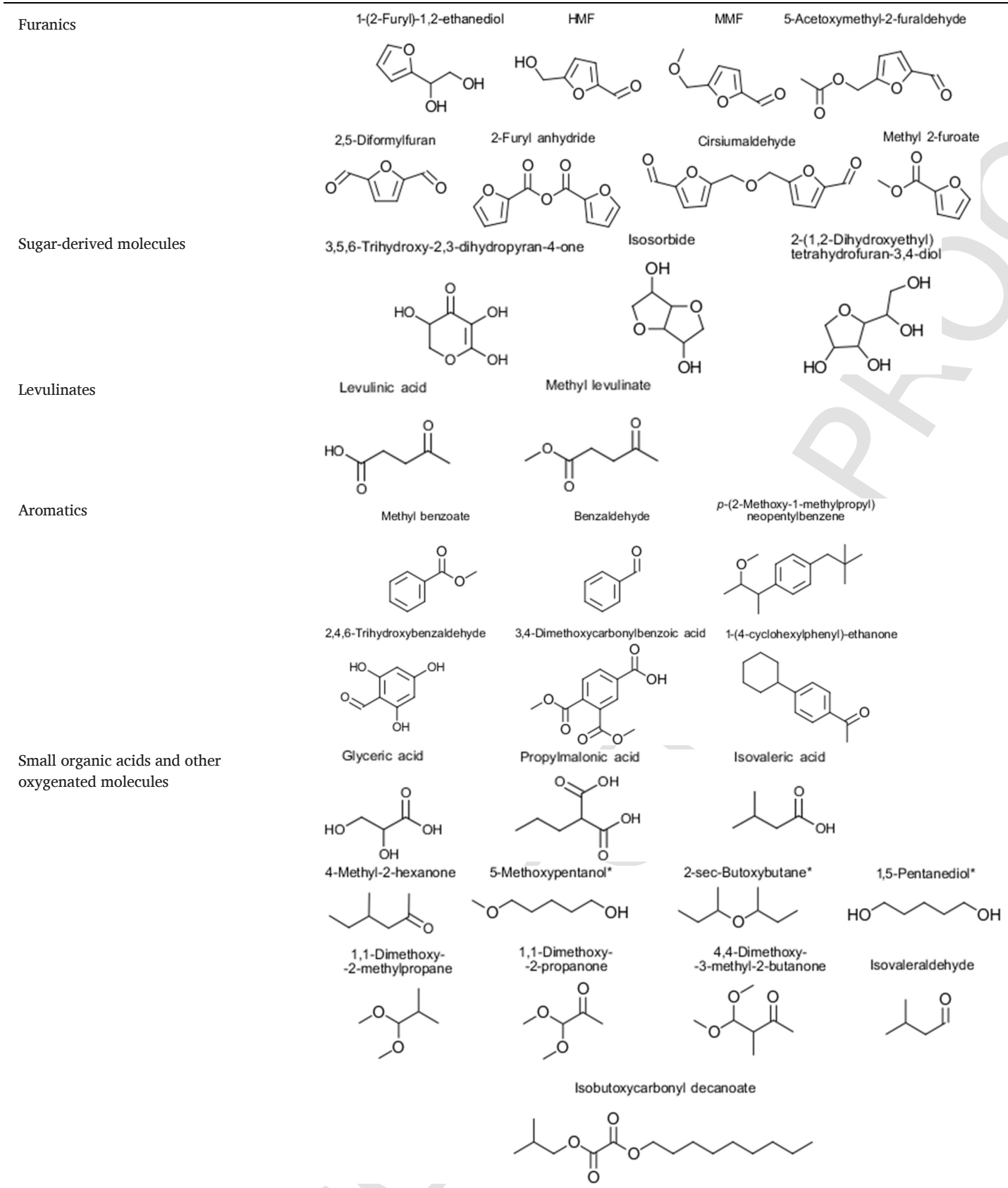

is merely a weak incorporation in the humins structure (terminal/easily cleaved). Nonetheless, the molecules were also observed at higher temperatures with increasing relative concentration, thus small quantities become part of the humins backbone. In particular, sugar dehydration products (e.g. 3,5,6-trihydroxy-2,3-dihydropyran-4-one,39 isosorbide) have been identified as decomposition products. Since the decompositions were run under neutral conditions (apart from in the presence of $10 \%$ acetic acid), these molecules are believed to be fragments of the humins structure. On the other hand, sugars are known to be derivatized for their analysis in GC-MS (poor volatility) [59], and it could be argued that they might be present and not detected. However, UPLC analyses did not show the presence of residual carbohydrates.

\section{Levulinates}

Similar to the sugar-derived molecules, levulinates are known to come from the acid-catalyzed decomposition of HMF (or similar), alongside the formation of formic acid. The detection of levulinic acid and the corresponding methyl ester suggest that also these molecules take part of the humins structure, as it was proposed but not asserted in literature $[34,42]$. The incorporation of other acid-catalyzed biomass side-products further stresses the random and complex nature of humins, which are favored under common chemical conversions of lignocelluloses and similar. 


\section{Aromatics}

Considering the low relative CSF of the humins employed in this study, the presence of aromatics may be surprising, although not completely unexpected. In fact, oxygen-containing aromatic functionalities were proposed in alkaline-treated humins, 33 and, in particular, 1,2,4-benzenetriol (see Scheme 5) was proposed as a minor reactive intermediate in the formation of humin by-products [39-41] In our decomposition mixtures, multiple oxygen-containing molecules were observed at both room and higher temperatures. The presence of triand tetra-substituted aromatics (i.e. 2,4,6-trihydroxybenzaldehyde and 3,4-dimethoxycarbonylbenzoic acid) may be a suggestion of the involvement of the ring-opening hydrolysis of HMF and dehydration to the trisubstituted benzene. In particular, this latter molecule would provide ortho-directing reactivity for further addition/condensation reactions, explaining the tetrasubstituted molecule. The presence of monosubstituted benzenes (e.g. benzaldehyde, methyl benzoate) at room temperature (and higher) decompositions instead suggest possible Diels-Alder reactivity of biomass compounds as seen for other bio-based molecules [60-63], as well as the hydrothermal carbons mentioned above [36]. For instance, methyl benzoate is known to be formed by the reaction between furan (highly volatile molecule) and methyl acrylate, possibly derived from other decomposition products, i.e. methyl acetate and formaldehyde [63]. This phenomenon can be observed in studies involving thermal treatment of humins, where FT-IR analyses showed that i) mild thermal treatment gave reduction of the typical $\mathrm{OH}$ stretching and increase of $\mathrm{C}=\mathrm{C}$ intensity peak [64], and ii) more intensive thermal treatment would yield polyaromatic structures, given by the disappearance of the FT-IR peak attributed to alkene out of plane bending [44]. These findings of aromatic structures not only give insight into the humins mechanism of formation, but also of the further reactivity of these plant-based by-products, suggesting the possibility of removing the superficial oxygen functionalities upon heating.

\section{Small organic acids and other oxygenated molecules}

All of the molecules in this class sustain the high oxygenated character of humin by-products. The molecules indicated with an asterisk (*) were observed only at high temperature transfer hydrogenolysis over the rNi catalyst, attributed to further decomposition reactions of the obtained molecules (e.g. HMF) and not humins. Among the remaining molecules, the incorporation of products of sugar dehydrations (e.g. oxalic/malonic fragments) can again be seen. Furthermore, the presence of acetals again suggests the existence of the mechanism proposed by Sumerskii et al. for humins formation. The ketone functionalities may be also attributed to acetal-type functional groups [34]. The 1,1-dimethoxy-2-propanone could be obtained via acid-catalyzed dolization of C6-sugars into dihydroxyacetone (DHA), followed by dehydration into pyruvic aldehyde (PY-A), and addition of methanol $[65,66]$, with the observance of glyceric acid supporting the proposed pathway as parallel equilibrium reaction of DHA into glyceraldehydes (GLYA, Scheme 6).

Pyruvic aldehyde, in particular, could partially resemble the DHH molecule proposed by Horvat [37], however requiring the cleavage of a carbon-carbon bond, which is not sustained by the mild combined severity of the process or the reaction conditions used in this study.

Small quantities ( $<3 \%$ of mass balance) of hydrocarbon-like molecules were also observed, in particular under high temperature treatment $\left(>180^{\circ} \mathrm{C}\right.$, transfer hydrogenolysis) and in the presence of a catalyst ( $5 \% \mathrm{Pd} / \mathrm{C})$. This could be similar to the observation of short aliphatic chains observed by van Zandvoort $[25,28]$, which represents the recalcitrant and fouling moieties of humins.

None of the observed molecules confirm the mechanism proposed by Patil and Lund involving DHH, although it cannot be disproven due to the high reactivity of said intermediate $[26,38]$. However, the decomposition products agree with the mechanisms involving acetal formation proposed by Sumerskii et al. [34], and the one involving the 1,2,4-benzenetriol intermediate [39-41]. Based on the decomposition products distribution, a very variegated humins structure can be deduced, involving starting molecules, main identified products, and other side-products of the acid-catalyzed hydrolysis of biomass.

\section{Proposed humins structure}

Incorporating all decomposition studies and the behavioral/literary knowledge of humin by-products, a structure of such molecules is proposed herein. The structure is representative of the possible functionalities and moieties that can appear in a particular batch, showing a higher heterogeneity of the humins structure as opposed to the furanic-based structure proposed in literature, becoming more similar to that of hydrothermal carbons [36]. In particular, furanics with (cyclic) acetal bonds are included in the structure, but also aromatics, sugar-derived molecules, and levulinates presenting ester and ether linkages. In particular, this structure represents the molecules that are easily cleaved by thermal and hydrogen-assisted decompositions. These observations are also in line with the FT-IR spectra of raw and thermally treated humins, where furanics are the major component [44,64]. The presence of furanic moieties linked by short aliphatic chains proposed by van Zandvoort et al. is not incorporated in the final humins structure, as evidence for their presence could not be found [25,28]. However, the observation of fouling and reactor plugging may hint at the existence of hydrocarburic linkages which are more prone to coking due to their recalcitrant nature. Overall, ring-opening hydrolysis of furanics

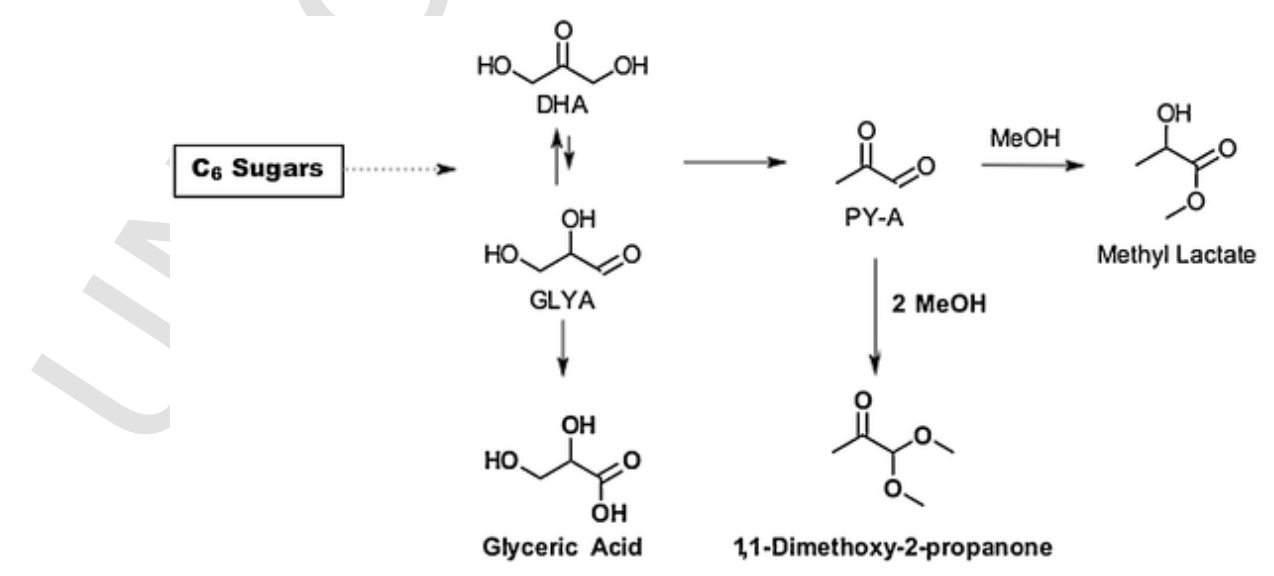

Scheme 6. Reaction pathway of the retro-aldolization of C6 sugars into pyruvic aldehyde. The molecules detected in this study are presented in bold. 
appears to be crucial in humins formation, giving a structure closer to hydrothermal carbons from carbohydrates (Scheme 2). Furthermore, the presence of hydroxyl and carbonyl groups favors condensation reactions to form humins, self-propagated by the presence of water. Hence, the presence of water seems crucial to humin by-product formation, as well as all reagents and products of biomass conversion via chemical transformations (Scheme 7).

\section{Conclusions}

The decomposition of humin by-products was achieved via thermal and hydrogen-assisted reactions in continuous flow under neutral $\mathrm{pH}$, yielding easily cleaved molecules representative of the key intermediates in the formation of humins. A down-up approach in general structural identification can be applied to oligomers and macromolecules with mild and harsher thermal and hydrogen-assisted decomposition, and pseudo-reconstruction of the overall structure is possible from the product mixture. In this work, it was found that humin by-products are heterogeneous molecules comprising a plethora of starting molecules and (by-)products of acid-catalyzed biomass conversion, as well as having multiple parallel mechanisms for their formation. The identification of key linkages such as acetal and ester suggest the presence of oxygen functionalities that could have potential as anchoring groups for catalytic systems [45], production of oxygen-containing materials/composites [46], or the removal of oxygen-containing groups upon carbonization [44]. Furthermore, humins and thermally-treated humins (foams) present fire behavior comparable to wood, thus have storage potential [67]. New applications for construction and automotive materials have also been investigated by combining humins with flax fibres [68]. As humins production can be minimized to a certain extent, upgrading the applications of these by-products is crucial to the development of a true circular economy, where value is added to any product.

\section{Experimental section}

Materials

Humins were provided by Avantium Chemicals B. V. (Amsterdam, The Netherlands) and employed without further purification. In particular, the humins were produced by the conversion of fructose in methanol. Ethyl acetate (99.9\%), acetonitrile (99.9\%) and methanol
(99.9\%) were purchased from Panreac AppliChem; 2-propanol (99.9\%) was bought from Fisher Scientific; glacial acetic acid from Panreac Quimica SA. All of the solvents were used as received.

\section{Humins solutions}

Different solutions of humins were made to achieve a concentration of $1 \mathrm{wt} \%$. In particular, ethyl acetate, $10 \%$ acetic acid in ethyl acetate, acetonitrile, methanol, and isopropanol were chosen as solvent systems for the decomposition reactions. The solutions were sonicated for $15 \mathrm{~min}$ and filtrated over a $0.45 \mu \mathrm{m}$ syringe filter in order to avoid the presence of heterogeneous molecules before their use in the continuous flow systems.

\section{Decompositions}

Thermal decompositions (blank) and transfer hydrogenolysis (humins in isopropanol) were carried out in a ThalesNano® Phoenix Flow Reactor ${ }^{\mathrm{TM}}$ (maximum operating temperature of $250^{\circ} \mathrm{C}$ ) at temperatures between $25-240^{\circ} \mathrm{C}$, and a flow of $0.2 \mathrm{~mL}$ min- $1(65.7 \mathrm{~s}$ of contact time). The system pressures were calculated applying the Clausius-Clayperon equation in order to ensure a liquid feed or sub/supercritical conditions. All hydrogenation reactions were run in a ThalesNano ${ }^{\circledR} \mathrm{H}-\mathrm{Cube}$ Mini Plus ${ }^{\mathrm{TM}}$ (maximum operating temperature of $100{ }^{\circ} \mathrm{C}$ ) at temperatures $25-90^{\circ} \mathrm{C}$, with or without 50 bar of system pressure, a flow of $0.3 \mathrm{~mL} \mathrm{~min}-1$ ( $43.8 \mathrm{~s}$ contact time) in the presence of hydrogen produced in by an electrocatalytic cell. The difference of contact time for the transfer hydrogenolysis and hydrogenation reactions were necessary to obtain significant conversions and stability of the reaction flow. i) Inert (TiO2), ii) $5 \% \mathrm{Pd} / \mathrm{C}$, and iii) RANEY ${ }^{\circledR N i}$ CatCarts ${ }^{\circledR}$ provided by ThalesNano ${ }^{\circledR}$ were employed $i$ ) for thermal decompositions, and $i$ ) and iii) for hydrogenation reactions.

\section{Analytical methods}

GC-MS analyses were employed for qualitative and semi-quantitative interpretations of decomposition products. In particular, a BR-5MS

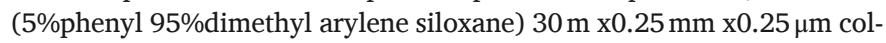
umn was employed. A PTV injector was used at $265^{\circ} \mathrm{C}$, split ratio of

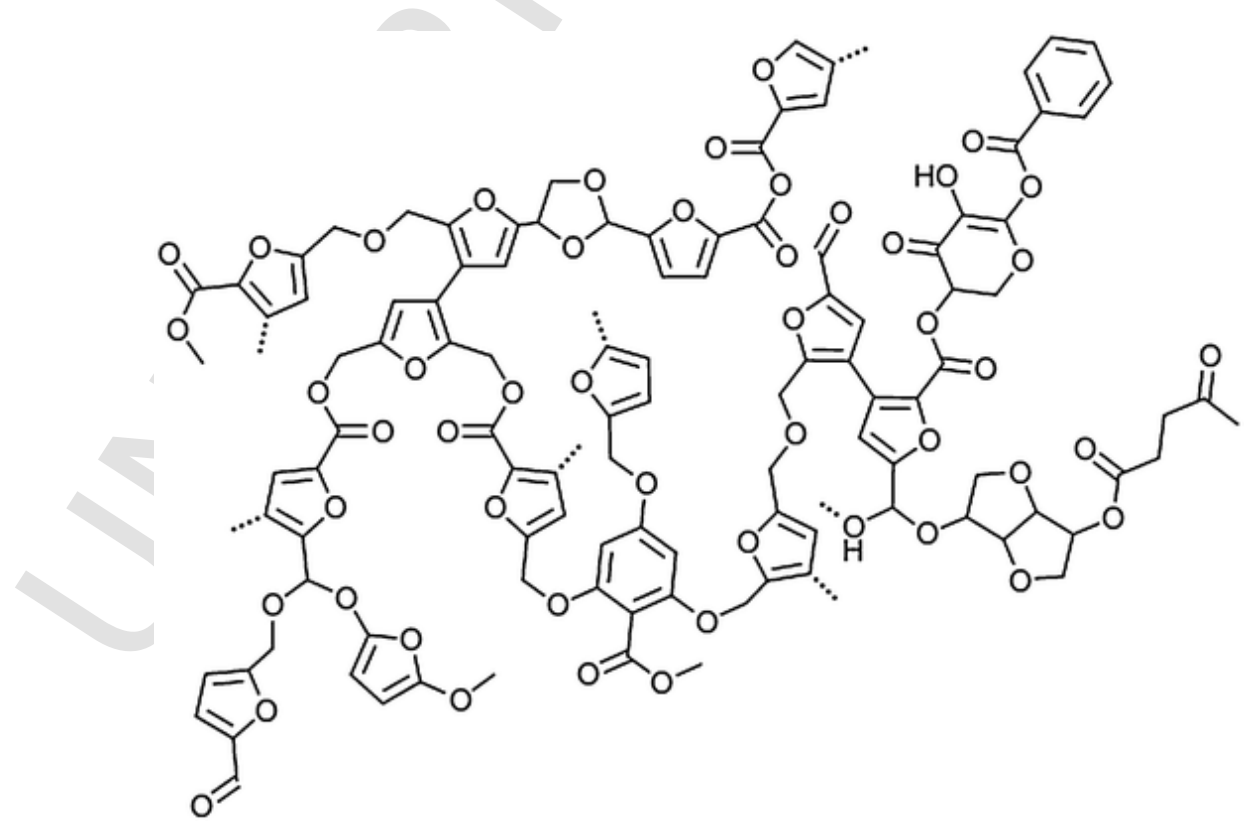

Scheme 7. Proposed humins structure based on the results of the (catalytic) decompositions and the structures given in literature. 
50 , and column flow of $1 \mathrm{~mL}$ min- 1 . The oven was set at $80^{\circ} \mathrm{C}$, followed by $3^{\circ} \mathrm{C}$ min- 1 to $200{ }^{\circ} \mathrm{C}, 10^{\circ} \mathrm{C}$ min- 1 to $250^{\circ} \mathrm{C}$, and $30^{\circ} \mathrm{C}$ min- 1 to $280^{\circ} \mathrm{C}$ (50 min). Ion source temperature was set to $275^{\circ} \mathrm{C}$ (transfer line $280^{\circ} \mathrm{C}$ ), and ionization energy $70 \mathrm{eV}$. The product mixtures were confirmed also on a HP- 5 column with the same oven conditions.

Only molecules with a reverse match factor (RMF) higher than 700 were considered for a qualitative analysis of the humins decomposition products (SD, S4-29). Semi-quantitative analyses were carried out by the ratio of the compound's total ion chromatogram (TIC) peak area divided by the sum of the areas of all products. As it contains sensitive information for intellectual property of the Avantium technology, the relative concentrations were normalized to the highest relative concentration. This way trends are further evidenced, rather than quantitative concentrations. Decomposition products were also analyzed GC and UPLC analyses in methods developed by the Analytical Team of the Renewable Chemistry department of Avantium matched against commercially available molecules. In particular, 1,4-dioxane $(3 \mathrm{mg} / \mathrm{mL})$ and saccharine $(8 \mathrm{mg} / \mathrm{mL})$ were used as external standard solutions, in a similar procedure previously reported [44]. These values were used to further confirm the speculations reported herein.

\section{Acknowledgements}

The authors strongly acknowledge the European Commission for the instauration of the Marie Skłodowska Curie Actions (MSCA), and in particular their financial support as in the project HUGS (H2020-MSCA-ITN-EID-675325). We would like to thank the people and service of the Servicio Central de la Investigación (SCAI) of the University of Cordoba, in particular Macarena Menéndez García, for the GC-MS analyses and method development; and the analytical team of the Renewable Chemistries Department of Avantium, in particular Sandra Constant, for GC and UPLC analyses and method development. The author would further like to acknowledge Rens Koning and Cevher Altug for their assistance in NMR and ATR-IR analyses of MMF, respectively. Lastly, the author would like to thank all the participants of the HUGS project for their joyful discussions on humins structure, reactivity, and valorization.

\section{Appendix A. Supplementary data}

Supplementary material related to this article can be found, in the online version, at doi:https://doi.org/10.1016/j.mcat.2019.110564.

\section{References}

[1]

World population projected to reach 9.8 billion in 2050, and 11.2 billion in 2100, Department of economic and social affairs, United Nations. https://www.un.org/development/desa/en/news/population/world-population-prospects-2017.html (Accessed 08 January, 2019).

[2] Y. Gao, X. Gao, X. Zhang, The $2{ }^{\circ} \mathrm{C}$ global temperature target and the evolution of the long-term goal of addressing climate change-from the United Nations framework convention on climate change to the Paris agreement, Eng. 3 (2017) 272-278, doi:10.1016/J.ENG.2017.01.022.

[3] L. Filiciotto, R. Luque, Biomass promises: a bumby road to a renewable economy, Curr. Green Chem. 5 (2018) 47-59, doi:10.2174/ 2213346105666180403145243.
[4] L. Wu, T. Moteki, A.A. Gokhale, D.W. Flaherty, F.D. Toste, Production of fuels and chemicals from biomass: condensation reactions and beyond, Chem. 1 (2016) 32-58, doi:10.1016/j.chempr.2016.05.002.

[5] M.J. Climent, A. Corma, S. Iborra, Conversion of biomass platform molecules into fuel additives and liquid hydrocarbon fuels, Green Chem. 16 (2014) 516-547, doi:10.1039/C3GC41492B.

[6] S. De, A.M. Balu, J.C. van der Waal, R. Luque, Biomass-derived porous carbon materials: synthesis and catalytic applications, ChemCatChem 7 (2015) 1608-1629, doi:10.1002/cctc. 201500081.

[7] F.D. Pileidis, M.-M. Titirici, Levulinic acid biorefineris: new challenges for efficient utilization of biomass, ChemSusChem 9 (2016) 562-582, doi:10.1002/ cssc. 201501405

[8] M.-F. Li, S. Yang, R.-C. Sun, Recent advances in alcohol and organic acid fractionation of lignocellulosic biomass, Bioresour. Technol. 200 (2016) 971-980, doi:10.1016/j.biortech.2015.10.004.

[9] L. Filiciotto, A.M. Balu, J.C. van der Waal, R. Luque, Catalytic insights into the production of biomass-derived side products methyl levulinate, furfural and humins, Catal. Today 302 (2018) 2-15, doi:10.1016/j.cattod.2017.03.008.

[10] S. Spierling, E. Knüpffer, H. Behnsen, M. Mudersbach, H. Krieg, S. Springer, S. Albrecht, C. Hermann, H.-J. Endres, Bio-based plastics-A review of environmental, social and economic impact assessments, J. Clean. Prod. 185 (2018) 479-491, doi:10.1016/j.jclepro.2018.03.014.

[11]

YXY technology, Avantium. https://www.avantium.com/yxy/ (Accessed 08 January, 2019).

[12]

Synvina. https://www.synvina.com/ (Accessed 08 January, 2019).

[13] S. Kang, J. Fu, G. Zhang, From lignocellulosic biomass to levulinic acid: A review on acid-catalyzed hydrolysis, Renew. Sustain. Energ. Rev. 94 (2013) 340-362, doi:https://doi.org/10.1016/j.rser.2018.06.016.

[14] F.A.H. Rice, Effect of aqueous sulfuric acid on reducing sugars. V. Infrared structure on the humins formed by the action of aqueous sulfuric acid on the aldopentoses and on the aldehydes derived from them, J. Org. Chem. 23 (1958) 465-468, doi:10.1021/jo01097a036.

[15] T.M.C. Hoang, E.R.H. van Eck, W.P. Bula, J.G.E. Gardeniers, L. Lefferts, K. Seshan, Humin based by-products from biomass processing as a potential carbonaceous source for synthesis gas production, Green Chem. 17 (2015) 959-972, doi:10.1039/C4GC01324G.

[16] S. Wang, H. Lin, J. Chen, Y. Zhao, B. Ru, K. Qiu, J. Zhou, Conversion of carbohydrates into 5-hydroxymethylfurfural in an advanced single-phase reaction system consisting of water and 1,2-dimethoxyethane, RSC Adv. 5 (2015) 84014-84021, doi:10.1039/C5RA18824E.

[17] X. Tang, Y. Sun, X. Zeng, W. Hao, L. Lin, S. Liu, Novel process for the extraction of ethyl levulinate by toluene with less humins from the ethanolysis products of carbohydrates, Energy Fuels 28 (2014) 4251-4255, doi:10.1021/ef5000497.

[18] K.L. von Hebel, J.-P. Lange, Process for Liquefying a Cellulosic Material US Patent 20110277378A1, November 17, 2011

[19] S. Eminov, A. Brandt, J.D.E.T. Wilton-Ely, J.P. Hallett, The highly selective and near-quantitative conversion of glucose to 5-hydroxymethylfurfural using ionic liquids, PLoS One 11 (2016), doi:10.1371/journal.pone.0163835 e0163835.

[20] J. Heltzel, S.K.R. Patil, C.R.F. Lund, Humin formation pathways, in: M. Schlaf, Z. Zhang (Eds.), Reaction Pathways and Mechanisms in Thermocatalytic Biomass Conversion II, Springer, Singapore, 2016, pp. 105-118.

[21] J. Herzfeld, D. Rand, Y. Matsuki, E. Daviso, M. Makjurkauskas, I. Mamajanov, Molecular structure of humin and melanoidin via solid state NMR, J. Phys. Chem. B 115 (2011) 5741-5745, doi:10.1021/jp1119662.

[22] S. Kang, X. Li, J. Fan, J. Chang, A direct synthesis of adsorbable hydrochar by hydrothermal conversion of lignin, Energy Sourc. A 38 (2016) 1255-1261, doi:10.1080/15567036.2011.631970.

[23] M. Sevilla, A.B. Fuertes, Chemical and structural properties of carbonaceous products obtained by hydrothermal carbonization of saccharides, Aust. J. Soil Res. 15 (2010) 4195-4203, doi:10.1071/SR10010.

[24] M. Sevilla, A.B. Fuertes, The production of carbon materials by hydrothermal carbonization of cellulose, Carbon 47 (2009) 2281-2289, doi:10.1016/ j.carbon.2009.04.026.

[25] I. van Zandvoort, E.J. Koers, M. Weingarth, P.C.A. Bruijnincx, M. Baldus, B.M Weckhuysen, Structural characterization of ${ }^{13} \mathrm{C}$-enriched humins and alkali-treated ${ }^{13} \mathrm{C}$ humins by 2D solid-state NMR, Green Chem. 17 (8) (2015) 4383-4392, doi:10.1039/C5GC00327J.

[26] S.K.R. Patil, J. Heltzel, C.R.F. Lund, Comparison of structural features of humins formed catalytically from glucose, fructose, and 5-hydroxymethylfurfuraldehyde, Energy Fuels 26 (2012) 5281-5293, doi:10.1021/ef3007454.

[27] T.M. Aida, Y. Sato, M. Watanabe, K. Tajima, T. Nonaka, H. Hattori, K. Arai, Dehydration of D-glucose in high temperature water at pressures up to $80 \mathrm{MPa}, \mathrm{J}$. Supercrit. Fluids 40 (2007) 381-388, doi:10.1016/j.supflu.2006.07.027. 
[28] I. van Zandvoort, Y. Wang, C.B. Rasrendra, E.R.H. van Eck, P.C.A. Bruijnincx, H.J. Heeres, B.M. Weckhuysen, Formation, molecular structure, and morphology of humins in biomass conversion: influence of feedstock and processing conditions, ChemSusChem 6 (2013) 1745-1758, doi:10.1002/cssc.201300332.

[29] S. Reiche, N. Kowalew, R. Schlögl, Influence of synthesis pH and oxidative strength of the catalyzing acid on the morphology and chemical structure of hydrothermal carbon, ChemPhysChem 16 (2015) 579-587, doi:10.1002/ cphc. 201402834

[30] G. Tsilomelekis, M.J. Orella, Z. Lin, Z. Cheng, W. Zheng, V. Nikolakis, D.G. Vlachos, Molecular structure, morphology and growth mechanisms and rates of 5-hydroxymethyl furfural (HMF) derived humins, Green Chem. 18 (2016) 1983-1993, doi:10.1039/C5GC01938A.

[31] A. Mija, J.C. van der Waal, J.-M. Pin, N. Guigo, E. de Jong, Humins as promising material for producing sustainable polysaccharide-derived building materials, Constr. Build. Mater. 139 (2017) 549-601, doi:10.1016/ j.conbuildmat.2016.11.019.

[32] I. van Zandvoort, E.R.H. van Eck, P. de Peinder, H.J. Heeres, P.C.A. Bruijnincx, B.M. Weckhuysen, Full, reactive solubilization of humin by-products by alkaline treatment and characterization of the alkali-treated humins formed, ACS. Sustainable Chem. Eng. 3 (2015) 533-543, doi:10.1021/sc500772w.

[33] S. Constant, C.S. Lancefield, B.M. Weckhuysen, P.C.A. Bruijnincx, Quantification and classification of carbonyls in industrial humins and lignins by ${ }^{19} \mathrm{~F}$ NMR, ACS Sustainable Chem. Eng. 5 (2016) 965-972, doi:10.1021/ acssuschemeng.6b02292.

[34] I.V. Sumerskii, S.M. Krutov, M.Y. Zarubin, Humin-like substances formed under conditions of industrial hydrolysis of wood, Russ. J. Appl. Chem. 83 (2010) 320-327, doi:10.1134/S1070427210020266.

[35] L. Filiciotto, G. de Miguel, A.M. Balu, A.A. Romero, J.C. van der Waal, R. Luque, Towards the photophysical studies of humin by-products, Chem. Commun. 53 (2017) 7015-7017, doi:10.1039/C7CC03679E.

[36] M.-M. Titirici, R.J. White, C. Falco, M. Sevilla, Black perspectives for a green future: hydrothermal carbons for environment protection and energy storage, Energy Environ. Sci. 5 (2012) 6796-6822, doi:10.1039/C2EE21166A.

[37] J. Horvat, B. Klaić, B. Metelko, V. Šunjić, Mechanism of levulinic acid formation, Tetrahedron Lett. 26 (17) (1985) 2111-2114, doi:10.1016/ S0040-4039(00)94793-2.

[38] S.K.R. Patil, C.R.F. Lund, Formation and growth of humins via aldol addition and condensation during acid-catalyzed conversion of 5-hydroxymethylfurfural, Energy Fuels 25 (2011) 4745-4755, doi:10.1021/ef2010157.

[39] X. Hu, C. Lievens, A. Larcher, C.Z. Li, Reaction pathways of glucose during esterification: effects of reaction parameters on the formation of humin type polymer, Bioresour. Technol. 102 (2011) 10104-10113, doi:10.1016/ j.biortech.2011.08.040.

[40] A. Chuntanapum, Y. Matsumura, Formation of tarry material from 5-HMF in subcritical and supercritical water, Ind. Eng. Chem. Res. 48 (2009) 9837-9846, doi:10.1021/ie900423g.

[41] G.C.A. Luijkx, F. van Rantwijk, H. van Bekkum, Hydrothermal formation of 1,2,4-benzenetriol from 5-hydroxymethyl-2-furaldehyde and D-fructose, Carbohydr. Res. 242 (1993) 131-139, doi:10.1016/0008-6215(93)80027-C.

[42] V.E. Tarabanko, M.A. Smirnova, M.Y. Chernyak, A.A. Kondrasenko, N.V. Tarabanko, The nature and mechanism of selectivity decrease of the acid-catalyzed fructose conversion with increasing the carbohydrate concentration, J. Sib. Fed. Univ. Chem. 8 (2015) 6-18.

[43] D.J. Hayes, J. Ross, M.H.B. Hayes, S.W. Fitzpatrick, The biofine process_-Production of levulinic acid, furfural, and formic acid from lignocellulosic feedstocks, in: B. Kamm, P.R. Gruber, M. Kamm (Eds.), Biorefineries-Industrial Processes and Products: Status Quo and Future Directions, Wiley-VCH Verlag GmbH \& Co., Weinheim, 2006, pp. 139-164.

[44] P. Tosi, G.P.M. van Klink, A. Celzard, V. Fierro, L. Vincent, E. de Jong, A. Mija, Auto-crosslinked rigid foams derived from biorefinery byproducts, ChemSusChem 11 (2018) 2797-2809, doi:10.1002/cssc.201800778.

[45] L. Filiciotto, A.M. Balu, A.A. Romero, E. Rodríguez-Castellón, J.C. van der Waal, R. Luque, Benign-by-design preparation of humin-based iron oxide catalytic nanocomposites, Green Chem. 19 (2017) 4423-4434, doi:10.1039/ C7GC01405H.

[46] J.M. Pin, N. Guigo, A. Mija, L. Vincent, N. Sbirrazzuoli, J.C. van der Waal, E. de Jong, Valorization of biorefinery side-stream products: combination of humins with polyfurfuryl alcohol for composite elaboration, ACS Sustain. Chem. Eng. 2 (2014) 2182-2190, doi:10.1021/sc5003769.

[47] Y. Wang, S. Agarwal, A. Kloekhorst, H.J. Heeres, Catalytic hydrotreatment of humins in mixtures of formic acid/2-propanol with supported ruthenium catalysts, ChemSusChem 9 (2016) 951-961, doi:10.1002/cssc.201600551.

[48] S. Kang, G. Zhang, Q. Yang, J. Tu, X. Guo, F.G.F. Qin, Y. Xu, A new technology for utilization of biomass hydrolysis residual humins for acetic acid production, Bioresources 11 (2016) 9496-9505, doi:10.15376/biores.11.4.9496-9505.

[49] E. de Jong, J.C. van der Waal, M.D. Boot, Fuel Composition Comprising Humins WO Patent, 2016130005A1, August 18, 2016.

[50] D.M. Carvalho, J.H. Queiroz, J.L. Colodette, Hydrothermal and acid pretreatments improve ethanol production from lignocellulosic biomasses, Bioresources 12 (2017) 3088-3107, doi:10.15376/biores.12.2.3088-3107.

[51] Z. Yang, Y.-B. Huang, Q.-X. Guo, Y. Fu, RANEY® Ni catalyzed transfer hydrogenation of levulinate esters to $\gamma$-valerolactone at room temperature, Chem. Commun. (Camb.) 49 (2013) 5328-5330, doi:10.1039/C3CC40980E.

[52] N. Baccile, G. Laurent, F. Babonneau, F. Fayon, M.-M. Titirici, M. Antonietti, Structural characterization of hydrothermal carbon spheres by advanced solid-state MAS ${ }^{13} \mathrm{C}$ NMR investigations, J. Phys. Chem. 113 (2009) 9644-9654, doi:10.1021/jp901582x.

[53] B. Girisuta, L.P.B.M. Janssen, H.J. Heeres, A kinetic study on the decomposition of 5-hydroxymethylfurfural into levulinic acid, Green Chem. 8 (2006) 701-709, doi:10.1039/B518176C.

[54] I. McManus, H. Daly, J.M. Thompson, E. Connor, C. Hardacre, S.K. Wilkinson, N. Sedaie Bonad, J. ten Dam, M.J.H. Simmons, E.H. Stitt, C. D'Agostino, J. McGregor, L.F. Gladden, J.J. Delgado, Effect of solvent on the hydrogenation of 4-phenyl-2-butanone over Pt based catalyst, J. Catal. 330 (2015) 344-353, doi:10.1016/j.jcat.2015.06.008.

[55] M. von Arx, T. Mallat, A. Baiker, Unprecedented selectivity behavior in the hydrogenation of an $\alpha, \beta$-unsaturated ketone: hydrogenation of ketoisophorone over alumina-supported Pt and Pd, J. Mol. Catal. A Chem. 148 (1999) 275-283, doi:10.1016/S1381-1169(99)00162-4.

[56] S. Agarwal, D. van Es, H.J. Heeres, Catalytic pyrolysis of recalcitrant, insoluble humin byproducts from C6 sugar biorefineries, J. Anal. Appl. Pyrol. 123 (2017) 134-143, doi:10.1016/j.jaap.2016.12.014.

[57] M. Miljković, Carbohydrates: Synthesis, Mechanisms, and Stereoelectronic Effects, Springer-Verlag, New York, 2009, pp. 143-167.

[58] S. Penczek, P. Kubisa, Cationic ring-opening polymerization: acetals, in: G. Allen, J.C. Bevington (Eds.), Comprehensive Polymer Science and Supplements, Elsevier Ltd., New York, 1989, pp. 787-812.

[59] A.I. Ruiz-Matute, O. Hernández- Hernández, S. Rodríguez-Sánchez, I. Sanz, M.L. Martínez-Castro, Derivatization of carbohydrates for GC and GC-MS analyses, J. Chromatogr. B 879 (2011) 1226-1240, doi:10.1016/j.jchromb.2010.11.013.

[60] E.M. Serun, S. Selvakumar, N. Zimmermann, M.P. Sibi, Valorization of 2,5-furandicarboxylic acid. Diels-Alder reactions with benzyne, Green Chem. 20 (2018) 1448-1454, doi:10.1039/C8GC00308D

[61] Y.-T. Cheng, G.W. Huber, Production of targeted aromatics by using Diels-Alder classes of furans and olefins over ZSM-5, Green Chem. 14 (2012) 3114-3125, doi:10.1039/C2GC35767D.

[62] L. Ni, J. Xin, K. Jiang, L. Chen, D. Yan, X. Lu, S. Zhang, One-step conversion of biomass-derived furanics into aromatics by Brønsted acid ionic liquids at room temperature, ACS Sustainable Chem. Eng. 6 (2018) 2541-2551, doi:10.1021/ acssuschemeng.7b04017.

[63] E. Mahmoud, J. Yu, R.J. Gorte, R.F. Lobo, Diels-Alder and dehydration reactions of biomass-derived furan and acrylic acid for the synthesis of benzoic acid, ACS Catal. 5 (2015) 6946-6955, doi:10.1021/acscatal.5b01892.

[64] A. Sangregorio, N. Guigo, J.C. van der Waal, N. Sbirrazzuoli, Humins from biorefineries as thermoreactive macromolecular systems, ChemSusChem 11 (2018) 4246-4255, doi:10.1002/cssc.201802066.

[65] P.Y. Dapsens, B.T. Kusema, C. Mondelli, J. Pérez-Ramírez, Gallium-modified zeolites for the selective conversion of bio-based dihydroxyacetone into C1-C4 alkyl lactates, J. Mol. Catal. A Chem. 388-389 (2014) 141-147, doi:10.1016/ j.molcata.2013.09.032

[66] F.S. Asghari, H. Yoshida, Acid-catalyzed production of 5-hydroxymethyl furfural from D-fructose in subcritical water, Ind. Eng. Chem. Res. 45 (2006) 2163-2173, doi:10.1021/ie051088y.

[67] A. Muralidhara, P. Tosi, A. Mija, N. Sbirrazzuoli, C. Len, V. Engelen, D. de Jong, G. Marlair, Insights on the thermal and fire hazards of humins in support of 
their sustainable use in advanced biorefineries, ACS Sustainable Chem. Eng. 6 (2018) 16692-16701, doi:10.1021/acssuschemeng.8b03971.

[68] A. Sangregorio, N. Guigo, J.C. van der Waal, N. Sbirrazzuoli, All 'green' composites comprising flax fibres and humins' resins, Compos. Sci. Technol. 171 (2019) 70-77, doi:10.1016/j.compscitech.2018.12.008. 